\title{
Forest-linked livelihoods in a globalized world
}

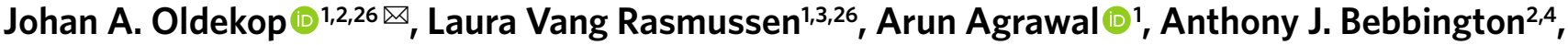 \\ Patrick Meyfroidt $\circledast^{5,6}$, David N. Bengston ${ }^{7}$, Allen Blackman ${ }^{8,9}$, Stephen Brooks ${ }^{10}$, lain Davidson-Hunt ${ }^{11}$, \\ Penny Davies ${ }^{12}$, Stanley C. Dinsi ${ }^{13}$, Lorenza B. Fontana ${ }^{14}$, Tatiana Gumucio ${ }^{15,16}$, Chetan Kumar ${ }^{17}$, \\ Kundan Kumar ${ }^{18}$, Dominic Moran ${ }^{19}$, Tuyeni H. Mwampamba ${ }^{20}$, Robert Nasi ${ }^{21}$, Margareta Nilsson ${ }^{22}$, \\ Miguel A. Pinedo-Vasquez ${ }^{16,23}$, Jeanine M. Rhemtulla ${ }^{24}$, William J. Sutherland ${ }^{25}$, Cristy Watkins ${ }^{1}$ and \\ Sarah J. Wilson'
}

\begin{abstract}
Forests have re-taken centre stage in global conversations about sustainability, climate and biodiversity. Here, we use a horizon scanning approach to identify five large-scale trends that are likely to have substantial medium- and long-term effects on forests and forest livelihoods: forest megadisturbances; changing rural demographics; the rise of the middle-class in low- and middle-income countries; increased availability, access and use of digital technologies; and large-scale infrastructure development. These trends represent human and environmental processes that are exceptionally large in geographical extent and magnitude, and difficult to reverse. They are creating new agricultural and urban frontiers, changing existing rural landscapes and practices, opening spaces for novel conservation priorities and facilitating an unprecedented development of monitoring and evaluation platforms that can be used by local communities, civil society organizations, governments and international donors. Understanding these larger-scale dynamics is key to support not only the critical role of forests in meeting livelihood aspirations locally, but also a range of other sustainability challenges more globally. We argue that a better understanding of these trends and the identification of levers for change requires that the research community not only continue to build on case studies that have dominated research efforts so far, but place a greater emphasis on causality and causal mechanisms, and generate a deeper understanding of how local, national and international geographical scales interact.
\end{abstract}

F orests provide essential livelihoods and environmental services. They harbour a disproportionate amount of the world's biodiversity, regulate key aspects of the global carbon cycle and weather patterns, and contribute directly to national incomes and the local livelihoods of millions of people worldwide. Their role in sustainability transitions is re-emphasized by multiple current international sustainability agendas. Forests can be linked to most-if not all-of the Sustainable Development Goals through contributions to ecosystem services, green economic opportunities, and social and environmental justice agendas ${ }^{1,2}$. Forests are also essential to the Paris Climate Agreement, ${ }^{3}$ the Aichi Biodiversity Targets and the Post-2020 Global Biodiversity Framework ${ }^{4,5}$. Further, the Bonn Challenge aims to bring under restoration 350 Mha of degraded lands globally by 2030, and the New York Declaration on Forests identifies 10 specific global forest goals $^{6}$. Forests are a key mechanism for mitigating climate change through forest protection, restoration and afforestation ${ }^{7.8}$. This prominent attention to forests, especially in human-dominated tropical and subtropical regions, creates a need for a comprehensive policy-oriented research agenda.

Research on forests and livelihoods has typically focused on trying to understand how household- or community-level dynamics, including rights to resources and land-use decisions, affect local livelihoods and forests ${ }^{9}$. However, new research on forests demonstrates the importance of links between human and natural systems at regional, inter-continental and global scales ${ }^{10}$. For example, demand for commodity crops in Europe, North America and emerging economies is driving environmental degradation in the Amazon, Congo Basin and Indonesian peatlands ${ }^{11}$. In turn, smoke from forest and peat fires in Indonesia affects human health in Southeast Asian countries $^{12}$. Identifying and understanding large-scale processes linked to forests and livelihoods with disproportionate effects on

\footnotetext{
'Forests and Livelihoods: Assessment, Research and Engagement (FLARE) Network, School for Environment and Sustainability, The University of Michigan, Ann Arbor, MI, USA. ${ }^{2}$ Global Development Institute, University of Manchester, Manchester, UK. ${ }^{3}$ Department of Geosciences and Natural Resource Management, The University of Copenhagen, Copenhagen, Denmark. ${ }^{4}$ Graduate School of Geography, Clark University, Worcester, MA, USA. ${ }^{5}$ Georges Lemaitre Centre for Earth and Climate Research, Earth and Life Institute, UCLouvain, Louvain-la-Neuve, Belgium. ${ }^{6}$ F.R.S.-FNRS, Brussels, Belgium. ${ }^{7}$ Strategic Foresight Group, Northern Research Station, USDA Forest Service, St Paul, MN, USA. ${ }^{8}$ Resources for the Future, Washington, D.C., USA. ${ }^{9}$ Inter-American Development Bank, Washington, D.C., USA. ${ }^{10}$ Office of Land and Urban, Bureau for Economic Growth, Education and Environment, U. S. Agency for International Development, Washington, D.C., USA. ${ }^{11}$ Natural Resources Institute, University of Manitoba, Winnipeg, Manitoba, Canada. ${ }^{12}$ Ford Foundation, New York, NY, USA. ${ }^{13}$ Network for Environment and Sustainable Development in Central Africa, Yaoundé, Cameroon. ${ }^{14}$ Politics Department, Newcastle University, Newcastle, UK. ${ }^{15}$ International Center for Tropical Agriculture (CIAT), Cali, Colombia. ${ }^{16}$ International Research Institute for Climate and Society, Earth Institute, Columbia University, Palisades, NY, USA. ${ }^{17}$ International Union for Conservation of Nature (IUCN), Washington, D.C., USA. ${ }^{18}$ Rights and Resources Initiative, Washington, D.C., USA. ${ }^{19} \mathrm{Global}$ Academy of Agriculture and Food Security, The Royal (Dick) School of Veterinary Studies and The Roslin Institute, University of Edinburgh, Edinburgh, UK. ${ }^{20}$ Institute for Ecosystems and Sustainability Research, National Autonomous University of Mexico (UNAM), Michoacán, Mexico. ${ }^{21}$ Center for International Forestry Research (CIFOR), Bogor, Indonesia. ${ }^{22}$ The International Land and Forest Tenure Facility, Stockholm, Sweden. ${ }^{23}$ Earth Innovation Institute, San Francisco, CA, USA. ${ }^{24}$ Department of Forest and Conservation Sciences, University of British Columbia, Vancouver, British Columbia, Canada. ${ }^{25}$ Department of Zoology, University of Cambridge, Cambridge, UK. ${ }^{26}$ These authors contributed equally: Johan A. Oldekop, Laura Vang Rasmussen. $\varpi_{e}$-mail: johan.oldekop@manchester.ac.uk
} 
sustainability, climate change solutions and biodiversity conservation is particularly important for policy and action.

For this Perspective, we used a systematic horizon scanning approach ${ }^{13}$ to identify and analyse five important trends that reflect large-scale human and environmental processes: forest megadisturbances; changing rural demographics; the rise of the middle class in low- and middle-income countries; increased availability, access and use of digital technologies; and large-scale infrastructure development. These trends are not yet widely understood and could act as both negative and positive disruptive forces for forests and forest livelihoods in the coming decade.

The research community must complement existing approaches to studying forests and livelihoods to understand how local livelihoods are influenced by large-scale socioeconomic and biophysical processes, including those driven by human-driven climate change and technological development. To help overcome current limitations, research on forests and livelihoods needs to implement three interrelated conceptual and methodological changes. These are: (i) a more systematic focus on causal analysis to identify and characterize causal relationships and interactions between factors causing changes in forest conditions and forest-linked livelihoods; and (ii) a closer examination of relationships across geographical and temporal scales to tease apart relative effects of different processes, their spatial heterogeneity and how they accumulate at local, national and international levels. Securing these deeper insights and unravelling how externally driven biophysical, economic and political processes affect local decision-making and forests will require (iii) greater use and integration of publicly available data, with household- or community-level case studies.

\section{Global trends and local communities}

The five trends that we identify represent human and environmental processes that are exceptionally large in geographical extent and magnitude, and difficult to reverse. These trends are driven by a complex set of factors that are external to rural communities at national, regional, inter-continental and global scales. This includes biophysical processes shaping environmental dynamics (for example, forest megadisturbances), as well as political and economic processes driven by private and public elites (for example, large-scale infrastructure development). Their effects result from the interaction between these external forces and local dynamics and responses. The five trends constitute new challenges to our understanding of forests and livelihood links. Gaining a better understanding of their potential effects and interactions provides a forward-looking lens with clear implications for policy and practice.

The trends we highlight were identified using an iterative horizon scanning approach. Horizon scanning exercises help identify emerging threats and opportunities ${ }^{13}$, and have been adopted by a range of public and private sector bodies ${ }^{14}$. Despite their demonstrated utility ${ }^{15}$, horizon scanning exercises remain underused, particularly in sustainable development fields undergoing rapid, complex and uncertain changes ${ }^{16}$. As a first step to identify emerging trends, the Forests and Livelihoods: Assessment Research and Engagement (FLARE) network held an open consultation using an online submission platform (led by J.A.O., L.V.R., A.A., C.W. and S.W.) during spring of 2016 and convened an expert panel to form a horizon scanning group (all remaining authors) working in forest and rural development sectors. Panel members were selected to represent a range of (i) academic as well as governmental and non-governmental institutions, including international donor organizations; (ii) subject expertise, including forest ecology and management, political science, economics and geography; and (iii) region-specific knowledge in Asia, Africa, Europe, and North and South America.

As part of the consultation, policy makers, practitioners and scholars-including expert panel members-were invited to submit, independently or in consultation with others, two to five trends they considered to be critical, emerging and linked to forest conservation and human well-being within the context of the post-2015 development agenda. Submissions were required to comply with three criteria: (1) be related to forests and wellbeing; (2) be formulated as a general topic area rather than as a research question, and (3) encompass a spatial and temporal scope that could be addressed through a realistic research design. The consultation led to 98 trends submitted by 136 people based in 23 countries in Asia, Africa, Europe and North and South America.

We used a modified Delphi technique ${ }^{13}$ to iteratively assess individual trends and produce a final shortlist. The horizon scanning group first independently ranked the 98 submitted trends through an online ranking exercise. These ranks were combined to produce an initial longlist of 36 trends (approximately a third of the individual submissions). Closely related or overlapping topics were combined at this stage. The horizon scanning group then met in person in Edinburgh in December 2016, where each trend was discussed, refined and ranked again in a day-long plenary session. The outcome of the Edinburgh meeting was a shortlist of 16 trends with highest mean rank. Sub-groups were then tasked to review and write summaries of each trend, and these were further refined, combined and agreed upon in a suite of e-mail exchanges to generate the final set of five, which we discuss here. No long- or shortlist could conceivably cover all emerging trends, nor could one expect full consensus on their importance. Further, no panel can claim perfect representation, and it is conceivable that a group with a different composition of disciplinary and geographical expertise might have arrived at somewhat different framings of global trends. However, given that they would have been working with the same 98 submissions, there is reason to expect that these framings would not have been substantially different. Furthermore, there is clear evidence in the literature that the five trends identified here are playing a substantial role in the creation of new agricultural, extractive and urban frontiers; the transformation of existing rural landscapes and practices; the opening of spaces for new conservation priorities; and the construction of radically different platforms for monitoring, evaluation and surveillance.

\section{Trend 1: forest megadisturbances}

Contemporary climate change policy and actions will not keep global temperature changes well below the $2{ }^{\circ} \mathrm{C}$ threshold ${ }^{17}$, the current target established under the Paris Agreement in 2015. The impact of climate change on forests and the role of forests in reducing or exacerbating climate change will increasingly place both forests and the communities that depend on them in the global spotlight. Exceptional droughts ${ }^{18}$ and excessive precipitation ${ }^{19}$ are already increasing forests' susceptibility to diseases and human-induced wildfires and floods. These stressors are causing forest defoliation and tree mortality ${ }^{20}$, and declines in forest productivity at unprecedented spatial scales (Fig. 1a). Consequences of significant tropical forest clearance are sometimes experienced thousands of kilometres from where disturbances occur ${ }^{21}$, and the cumulative effects of these processes are threatening both an extraordinary number of species ${ }^{22}$ and the provision of forest-derived ecosystem services at global, regional and local scales ${ }^{23}$. Furthermore, there is accumulating evidence about the links between forest disturbance, human-forest system interactions and the emergence of zoonotic diseases with the potential to spread globally ${ }^{24}$. While the exact origins of COVID-19 are still to be determined, it has demonstrated, together with other zoonotic diseases like SARS, HIV and Ebola, the devastating social and economic significance of pandemics, and highlighted another crucial aspect of the linkages between human-forest relations and global change.

Policy responses to these forest megadisturbances will require strategic use of particular types of forests (for example, intact and 

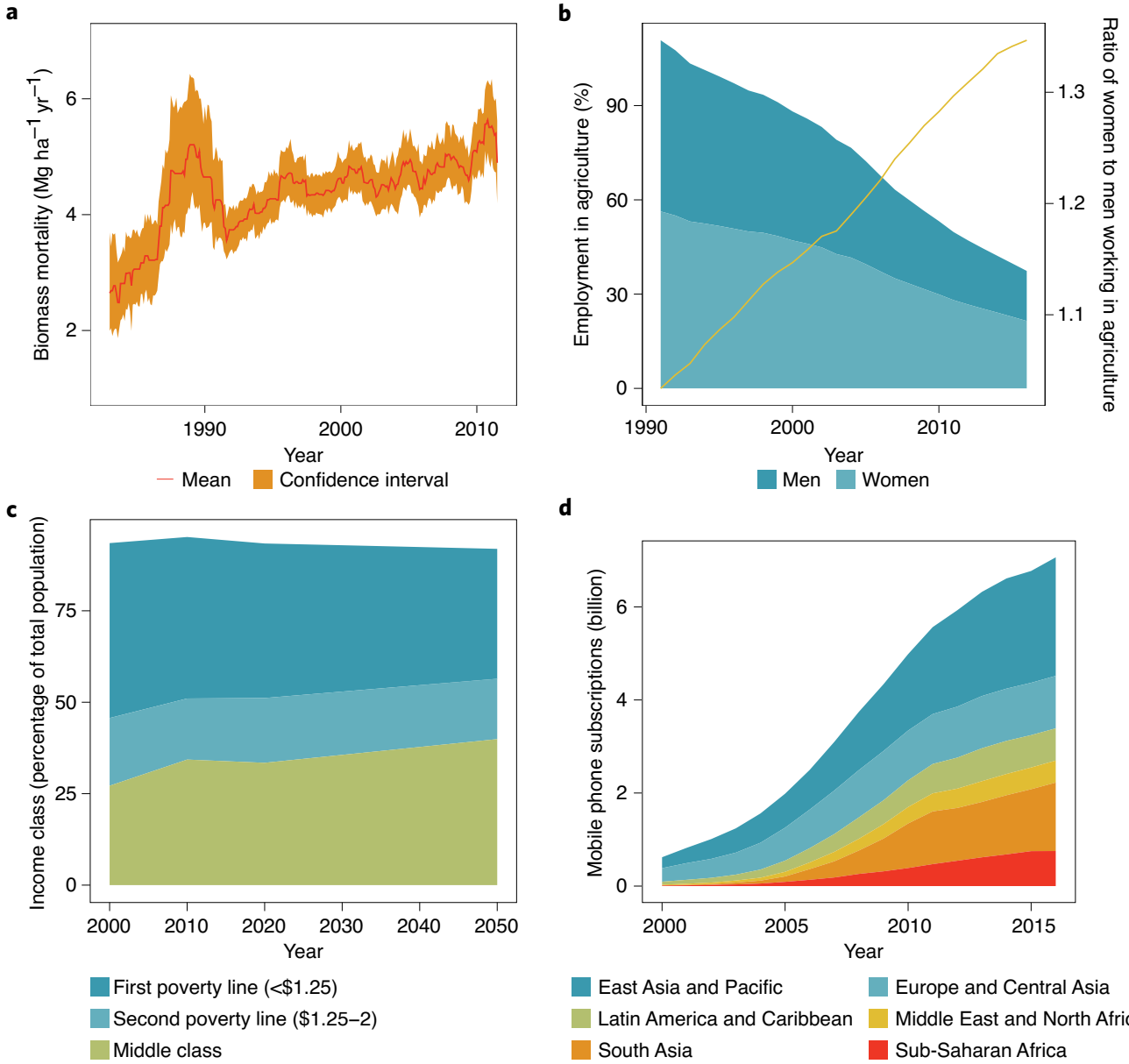

d

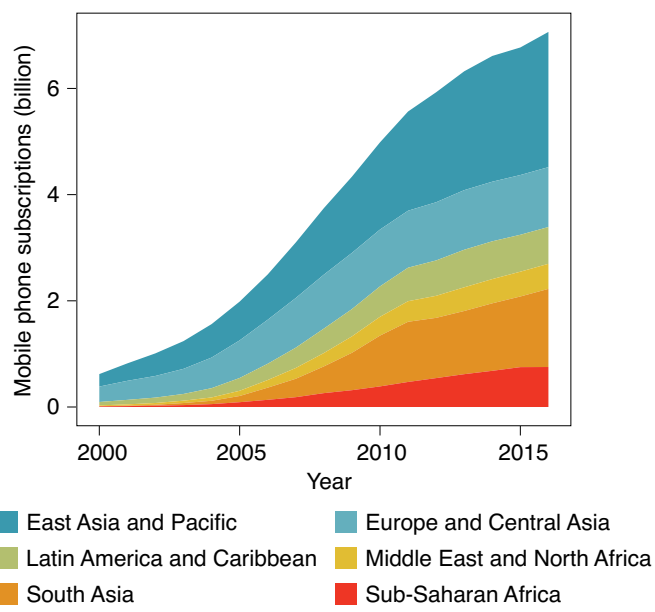

Fig. 1 | Changes in key socioeconomic and biophysical trends. a, Increased biomass mortality in 321 forest plots in the Amazonian rainforest. Adapted


mobile phone subscriptions ${ }^{73}$.

second-growth forests, agroforestry and plantations) for livelihood support, conservation and climate change mitigation-including bioenergy production, forest protection, biodiversity conservation and carbon capture and storage. Transformed forest landscapes and forest-based climate change mitigation and adaptation effortsincluding wide-scale forest landscape restoration initiatives-will provide new opportunities and challenges for forest-dependent communities. Opportunities and challenges are likely to arise from efforts to align (or not to align) forest conservation and restoration with other priorities of sustainability agendas, including equity, poverty alleviation and rights to land and resources. For example, the Bonn Challenge, launched in 2011 and extended in 2014 by the New York Declaration on Forests, has a target of restoring 350 million hectares across the globe by 2030 , which equals $3 \%$ of the global ice-free land area. However, in many low- and middle-income countries, where land is often in short supply and subject to multiple different demands, including food production and conservation, restoration will have to be implemented synergistically with other land uses ${ }^{25}$.

\section{Trend 2: changing rural demographics}

Forest-reliant communities are experiencing an unprecedented exodus-predominantly of working-aged $\operatorname{men}^{26}$. For example, rural to urban migration in China after the easing of movement restrictions (reformation of the 'hukou' system ${ }^{27}$ ) represents one of the largest movements of people in human history (Fig. 1b), and is leading to the feminization of rural landscapes and forest management. The effects of these demographic shifts on forest dynamics, such as forest resurgence on previously used agricultural lands, and the ways in which such demographic shifts alter participation and voice in forest decision-making are not well understood. Emerging research shows that people's movements may be linked to the mobilization of new economic resources, knowledge, values, technologies and skills ${ }^{26}$. Changing demographic patterns influence not just the livelihoods of forest communities but also macro-governance institutions that will shape future social and environmental transformations of forested landscapes. For example, international migration is driving reforestation in $\mathrm{Nepal}^{28}$, changing community forest management institutions in $\mathrm{Mexico}^{29}$ and driving shifts from subsistence to commodity crop monocultures in agricultural systems in the Philippines ${ }^{30}$.

The socioeconomic and environmental effects of these demographic changes predominantly manifest themselves at subnational and local scales. However, the drivers of rural demographic changes are complex and multi-scalar ${ }^{31}$, encompassing local 'push' (for example, poverty and insecure livelihood options driven by climate change) and 'pull' (for example, prospects of increased and more diverse incomes) factors mediated by national- and international-level processes, including the development of transportation networks and national and international labour markets as well as related institutions (for example, recruitment agencies). New possibilities and risks for conservation, degradation and governance are emerging as a result of linkages and circular flows among people who have left, those who have stayed and those who have returned. 
While rural populations globally are declining, urban populations are increasing rapidly. The land sparing hypothesis asserts that intensification of production on existing lands can allow for meeting increased demand from steep population growth while generating opportunities for more effective forest conservation elsewhere in the landscape ${ }^{32}$. Land sparing should in theory facilitate new possibilities for forest conservation, yet beyond the issue of the net demand for land, rural population shifts to urban centres can be related to deforestation by creating increased urban demand that has sometimes been met through new large industrial agricultural projects in depopulated areas ${ }^{33}$.

\section{Trend 3: rise of the middle class in low- and middle-income countries}

The middle class in low- and middle-income countries is forecast to grow to 4.9 billion people by 2030 , comprising over half of the projected global population ${ }^{34}$ (Fig. 1c). This trend generates a new source of demand for commodities with large forest footprints (for example, meat and palm oil) as well as a new source of investment for agricultural land and support for conservation. The growth in demand by this rapidly growing middle class will surpass previous global estimates, putting increasing pressure on land and other resources ${ }^{35}$. Growing demand for commodities has already prompted large-scale, corporate-led land acquisitions for industrial production of cattle, soy and palm oil in Latin America, Africa and Southeast Asia ${ }^{36}$. Globally, 27\% of all forest disturbance between 2001 and 2015 was associated with commodity-driven deforestation $^{37}$. Further growth in demand and an accompanying culture of consumerism will alter local and global consumption patterns, with potentially severe effects on deforestation rates, emissions, wildlife populations, ecosystem services and rural communities. Large-scale land acquisitions in Africa, Southeast Asia and Latin America are also being driven by urban elites with the financial and political capital to acquire and consolidate farms ${ }^{38}$. This trend is being accompanied by new countervailing interests in protecting nature and forests as conservation values become more widespread and recognized ${ }^{39}$.

The EAT-Lancet Commission recently argued that food in the Anthropocene represents one of the greatest health and environmental challenges of the twenty-first century ${ }^{40}$. Despite us having seen reductions in hunger, improved life expectancy, and falling infant and child mortality rates in recent decades as well as decreased global poverty, these health benefits are now being offset by shifts to unhealthy diets that are high in calories and heavily processed foods. Rapid urbanization and increasing incomes (accompanied by growing demands for processed foods and animal source foods) are partly driving these shifts to unhealthy diets. The global transformation to healthy diets from sustainable food systems suggested by the EAT-Lancet Commission requires that the global consumption of fruits, nuts, vegetables and legumes will have to double ${ }^{41}$. Given that these food groups often are low yielding and include many food items that are frequently sourced from the wild, it is critical to understand the role of forests and trees in securing sufficient supply of these food groups. Indeed, forests and agriculture are typically managed as separate sectors, although the contribution of forests to food and agricultural production via environmental services at local and global scales should receive greater recognition and policy support $^{41}$. A deeper understanding of how forests and agroforestry systems contribute to food and nutritional security-both in rural and urban areas-is needed to inform policy debates on food and nutrition, and promote a more coordinated management across agricultural and forest sectors.

\section{Trend 4: rise in the availability, accessibility and use of digital technologies}

Information and communications technologies (ICTs), including personal computers, tablets, cell phones, web tools, smart technologies and social media platforms, are likely to have transformational impacts on the forest sector in the coming decade. Global ICT access has grown exponentially: between 2000 and 2016 alone, internet use and mobile cellular subscriptions saw a sevenfold increase, with much of that growth occurring outside industrialized countries ${ }^{42}$ (Fig. 1d). ICTs that collect, compile and disseminate forest sector data are increasingly accurate, sophisticated and easy to use, and include land mapping, real-time satellite data and analyses as well as large-scale, crowd-sourced data on land cover changes and forest conditions. To accommodate and attract new users, data providers like Global Forest Watch (https://www.globalforestwatch.org) are making data more accessible and easy to analyse. Similarly, monitoring platforms like TRASE (https://trase.earth) track increasingly detailed information about international commodity supply chains, including trading companies, to monitor national and corporate transparency commitments.

These changes can benefit a wide range of forest sector stakeholders: policymakers needing better evidence for decision-making; oversight bodies needing to monitor compliance; non-governmental actors seeking to monitor sustainable production chains of key commodities and products, as well as advocating for conservation and social equity; forest managers interested in improved productivity and marketing; and local communities and indigenous peoples interested in protecting their forests and livelihoods ${ }^{43}$. Conversely, novel tools and technologies can also aid those involved in illicit activities linked to deforestation, including illegal logging, mining and drug trafficking to evade controls and detection ${ }^{44}$.

ICTs are supporting the surveillance and certification of global production networks (for example, palm oil), and this is increasing the regulatory control of forest-based products and actors threatening forests. However, the 'cleaning up' of supply chains and 'zero deforestation targets' (that is, producing and sourcing commodities that do not involve forest clearance) can concentrate corporate large-scale production on already deforested lands and lead to the displacement of smaller producers onto more marginal lands ${ }^{45}$. Forced displacement of local communities can likewise fuel deforestation, as displaced communities are forced to seek other lands to sustain their livelihoods, and also exacerbate environmental conflicts, as communities seek to maintain control over their small-holdings and/or communal forests ${ }^{46}$. It is also important to understand how attempts to reduce deforestation through supply chain governance might displace land-use pressure from humid tropical forests and peatlands into other ecosystems ${ }^{47}$ (for example, dry forests and savannahs).

\section{Trend 5: large-scale infrastructure development}

To accommodate demand for energy, natural resources and transport, many countries are planning ambitious growth in these sectors and related infrastructures ${ }^{48}$. Large-scale international infrastructure projects, such as the Chinese-led Belt and Road Initiative, are likely to have transformational impacts on forests and rural communities ${ }^{49}$. These projects are driven and made possible by national political and economic elites, the increased use of public-private financing mechanisms, international financial institutions, geopolitical interests and the support of subnational elites ${ }^{48}$. At least 25 million kilometres of new roads to facilitate the flow of commodities to and from transport hubs are anticipated globally by 2050-equivalent to a $60 \%$ increase in the total length of roads compared to 2010 $\left(\right.$ ref. $\left.{ }^{50}\right)$. Governments in the Amazon basin alone are developing 246 new hydroelectric dams ${ }^{51}$ (in comparison with the now 191 in existence; Fig. 2). Approximately $48 \%$ of protected area downgrading, downsizing and degazettement (PADDD) events in the basin are linked to dams ${ }^{52}$. Large-scale infrastructure is frequently the driver of other natural resource extraction drivers of forest loss ${ }^{48}$. Illegal mining activities are also expanding rapidly, notably in remoter areas of South America, Africa and Indonesia ${ }^{53}$. At least 106 
a

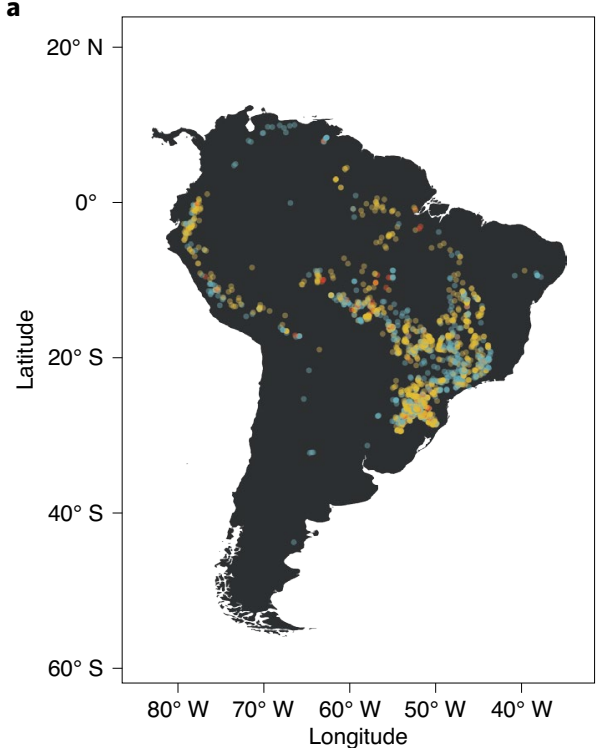

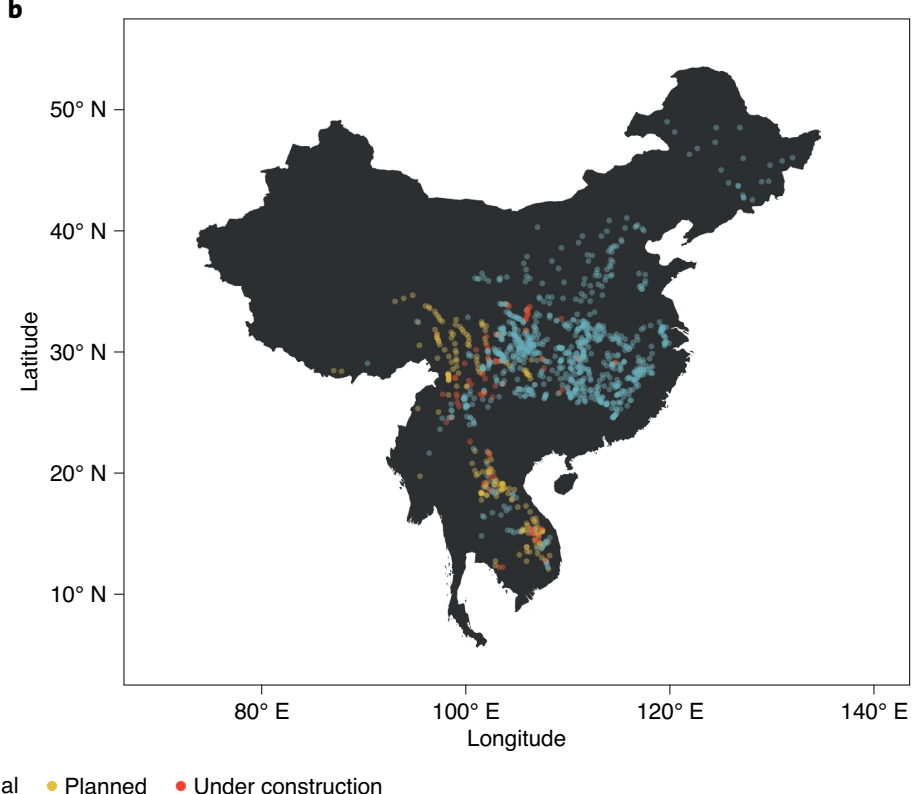

Fig. 2 | Dam construction in forest-rich regions. a,b, South America (a) and China and mainland Southeast Asia (b) are two forest-rich regions where the majority of the world's hydropower infrastructure is currently being developed (https://www.globalforestwatch.org).

probable incidences of PADDD (24\% of recorded incidences) caused by mining in the Amazon alone have been identified ${ }^{52}$. This growth in infrastructure, hydroelectric power development and mining leads to forest loss, displaces forest-residing peoples, disrupts livelihoods and provokes social conflicts as communities lose access to land and resources ${ }^{54}$. For example, the Chacorão dam of the Tapajos hydroelectric complex in Brazil will flood over 18,000 ha of the indigenous territory of the Munduruku people who have contested this project ${ }^{55}$. Infrastructure and resource extraction investments are also linked to systemic corruption that clouds transparency in natural resource governance ${ }^{56}$, as in the ongoing Lava Jato corruption scandal that has shown the extent of paybacks and trading of favours linked to large-scale infrastructure and hydrocarbon investment across Latin America.

\section{Expanding case study research}

The five trends outlined above parallel a shift in the research agenda on social and environmental issues in tropical forests, which has departed from the notion of smallholders as principal agents of deforestation towards a focus on national development models, complex global production networks and large-scale private investments. However, data collection efforts and analyses to assess forest-livelihood links and forest governance outcomes have typically focused on household- or community-level dynamics through case studies and collections of case studies ${ }^{9,57}$. These efforts have helped spur theoretical advances and have identified key drivers of livelihood changes, poverty and their links to forest cover change in forest landscapes. Understanding how the five trends noted above affect forests and livelihoods will require expanding substantially on household- and community-level case studies (or collections of case studies) to understand externally driven biophysical, economic and political processes, and their effects on local decision-making processes. Large sample size, country-level studies combining publicly available data sources-such as national census data-can provide additional insights to local case study analyses. For example, recent national-level studies leveraging multiple secondary datasets in Nepal demonstrate the mechanisms through which international migration drives reforestation in the country, and how poverty moderates the effectiveness of decentralized forest management in reducing deforestation ${ }^{28,58}$. A similar analytical approach combines multiple data sources to understand how road networks, agriculture suitability and poverty influence protected area effects on forests and livelihoods in Thailand and Costa Rica ${ }^{59}$. These national-level approaches complement local case-study-based research by systematically testing for the role of biophysical and socioeconomic factors in shaping environmental and social outcomes of forest-related interventions in the context of large-scale demographic changes.

\section{A greater emphasis on causality}

Identifying and estimating causal relationships in forest landscapes is necessary for the development of a stronger evidence base that can better inform policy decisions but remains a challenge ${ }^{60}$ for two key reasons. First, while qualitative assessments of forests and livelihoods provide strong causal insights on drivers of social and environmental change, they are unable to generate estimates that are comparable across space and over time. Second, many quantitative studies of forests and livelihoods suffer from small sample sizes; often include too few predictor variables to accurately describe the broader socioeconomic contexts being studied, or to control for key factors that might themselves act as key drivers of forests and livelihood changes; and tend to focus on single points in time ${ }^{61}$. Small sample sizes and model misspecifications (often driven by data limitations, particularly of socioeconomic data that are collected less frequently than forest cover data, for example) can lead to potential statistical bias and over-simplification of causal pathways, including inattention to mechanisms that may act as precursors of factors affecting forest-livelihood links ${ }^{62}$ (for example, migration patterns ${ }^{28}$ ). Quantitative studies on forests and forest livelihoods have also tended to rely on reverse causal questions (or causes of effects-'what factors cause forest-livelihood changes'-as opposed to forward causal questions or effects of causes-'what changes does $x$ prompt in forests, livelihoods and their relationships?'63). Approaches determining causes of effects are particularly well suited for hypothesis generation by identifying key relationships between variables of interest. In contrast, approaches that determine effects of causes are often better suited for hypothesis testing because they 


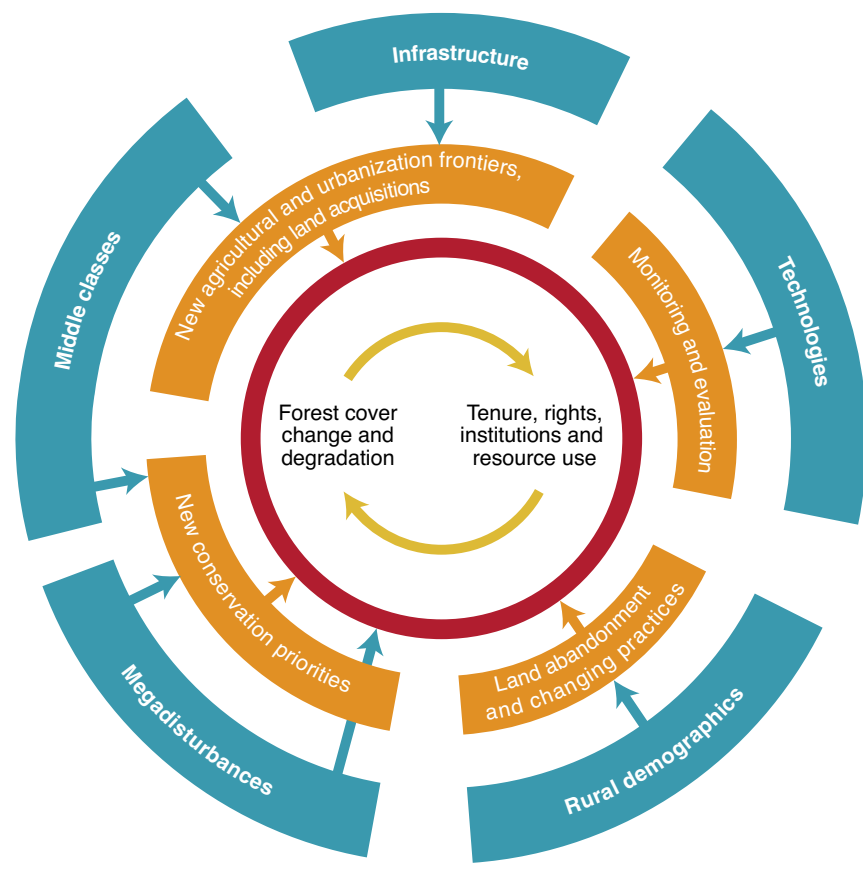

Fig. 3 | Forest-livelihood linkages in a globalized world. Five large-scale socioeconomic and biophysical trends (blue shapes) likely to influence forests and livelihoods (area inside the red circle) through a series of mechanisms (orange shapes)

can provide more precise estimates of specific factors being analysed. However, both methods run the risk of corroborating theory if statistical models are poorly defined.

Generating more robust and comprehensive causal analyses will require: (i) a better balance between hypothesis generation and hypothesis testing, including a stronger integration of research methods (for example, between qualitative and quantitative methods to generate mixed methodologies), and use of both classic qualitative studies as well as emerging tools and approaches not widely used in the forest-linked livelihoods field, including novel tools for systematic qualitative analyses ${ }^{64}$, machine learning ${ }^{65}$, modelling approaches $^{66}$ and randomized control trials ${ }^{67}$; (ii) strengthening existing data platforms (for example, TRASE (https://trase.earth) and the World Bank Microdata Library ${ }^{68}$ ), and better integrating secondary socio-economic and biophysical datasets to assess joint livelihood and forest outcomes (for example, ref. ${ }^{58}$ ); (iii) a more careful design of quantitative and qualitative primary data collection efforts that can be combined with existing datasets; and (iv) closer partnerships among different stakeholders to ensure that research can be co-produced and leveraged in advocacy strategies. Approaches that can leverage the relative strengths of different datasets and methods are most likely to identify new and better strategies of change for advocacy and policy interventions.

\section{Deeper exploration of geographical and temporal scales}

Although spatiotemporal scales are inherently integrated into multiple frameworks to address human-environment interactions, existing empirical approaches have not been consistent nor explicit in the incorporation of scale into forests and livelihoods research. For example, estimates of the economic contribution of forests to national gross domestic product (GDP) exist at the national administrative scale, but it is not clear how these national-level figures link to household-level estimates of forest benefits or forest contributions to local incomes and economies. And by contrast, although household-level surveys provide estimates of forest contributions to local livelihoods, it is generally not possible to relate these to national-level estimates of contributions to $\mathrm{GDP}^{69}$. As a consequence, tracking how different economic and ecological processes and factors, including the trends discussed here, affect forests and livelihoods across scales remains difficult. The combination of various secondary data sources, including national census data and representative household surveys-such as the World Bank's Living Standards Measurement Survey or USAID's Demographic Health Survey-with national-level datasets, holds enormous promise for multi- and cross-scale empirical analyses. These data are collected regularly over time, and can be iteratively aggregated at different administrative units (for example, from villages $<$ municipalities $<$ districts) and merged to cover spatial gaps and measure changes over time. The reconciliation of evidence across spatiotemporal scales does confront substantial challenges because different socioeconomic data collection efforts are often inconsistent in both space and time, with different waves of household data collections designed to be representative cross-sectional samples rather than panel datasets. Emerging technologies-such as machine learning and big data analytics-promise potential avenues to reconcile some of these spatial and temporal incongruencies ${ }^{70}$. Compilation efforts to combine disparate high-spatial resolution datasets will be particularly useful to understand the relative effects of factors and processes co-occurring in space and time-such as the five trends that we advance. Furthermore, they are also particularly useful to understand social and spatial heterogeneity of effects and outcome patterns, and also spill over effects of changing forest-livelihood relationships.

\section{Concluding remarks}

The five trends above emphasize the importance of novel actors (middle-class citizens as well as emerging national elites in lowand middle-income countries), new technologies (ICTs and digital monitoring platforms), increasing mobility patterns (changing gender relations and circular knowledge exchanges) and changing dynamics (forest megadisturbances and accelerating infrastructure development). They also highlight key mechanisms through which these trends likely affect forests and forest livelihoods (Fig. 3 ), including new conservation priorities, shifting agricultural and extractive frontiers, land abandonment and changing agricultural practices, and monitoring and evaluation tools.

Gaining a better understanding of how forests and forest livelihoods are being affected by the five trends we identify is critical for policy and advocacy at local, national and international scales. Building on case study research, placing greater emphasis on causality and integrating different knowledges across geographical and temporal scales could provide a more detailed understanding of long-term social and environmental outcomes at multiple levels, and generate a more nuanced understanding of the complex forest-livelihood synergies and trade-offs in relation to multiple Sustainable Development Goals. Building a research agenda with the potential for policy impact will require redoubling efforts to strengthen multiple types of collaborations, including between social and natural scientists, between scientists and policymakers, and partnerships that recognize the validity and legitimacy of both local and global knowledge, including decolonizing methodologies and participatory approaches that help counter pervasive western forest management models. Such changes in approach are vital if the research community is to find ways of working together with forest communities and their allies that adequately link specific placed-based outcomes to global trends.

Building such links might constitute a challenge given rising global protectionist, nationalist and authoritarian trends, which are making it more difficult for civil society organizations to legally register, get work permits or access funding in places affected by rising competition over natural resources such as water, food, fuel and 
land. Where pressures on forests grow for reasons of food, energy and minerals, community-based organizations and individuals protecting forests are also subject to harassment, criminalization and, far too frequently, murder at the intellectual hands of national and subnational elites ${ }^{71,72}$.

In the medium- to long-term future, the space for civil society organizations is likely to be increasingly contested. It is therefore essential that, in addition to their work with civil society organizations, the research community also consider engaging with novel partners such as investigative journalists; anti-corruption commissions; rights-based lawyers; civil engineering companies; ministries of roads, mines and energy; and financiers. Such interactions hold the potential to yield new insights, different modes of engaging policy and the public sphere, and novel conversations capable of offsetting and contesting trends that are closing civic spaces related to forest governance ${ }^{54}$.

The five trends we highlight point to the importance of understanding how large-scale and potentially competing public and private demands on forest landscapes for commercial, development and conservation purposes (for example, rapid expansion of hydroelectric power development and increasing forest restoration pledges) interact with local claims for land and resource rights. In this context, it is also paramount to rethink how and with what tools (for example, better digital forest monitoring platforms, hand-held devices and drones) and governance systems rural communities and civil society organizations can defend forests, local livelihoods and the increasingly contested economic, cultural and political spaces that forests represent ${ }^{71}$. Future capacities to identify and prioritize critical leverage points hinge on better theories of human and natural systems that can help identify the interventions necessary for sustainability transitions.

Received: 18 December 2019; Accepted: 30 October 2020; Published online: 30 November 2020

\section{References}

1. Timko, J. et al. A policy nexus approach to forests and the SDGs: tradeoffs and synergies. Curr. Opin. Env. Sust. 34, 7-12 (2018).

2. Katila, P. et al. Sustainable Development Goals: Their Impacts on Forests and People (Cambridge Univ. Press, 2019).

3. Grassi, G. et al. The key role of forests in meeting climate targets requires science for credible mitigation. Nat. Clim. Change 7, 220-226 (2017).

4. Butchart, S. H. M. et al. Shortfalls and solutions for meeting national and global conservation area targets. Con. Lett. 8, 329-337 (2015).

5. Zero Draft of the of post-2020 Global Biodiversity Framework (Convention on Biological Diversity, 2020).

6. Suding, K. et al. Committing to ecological restoration. Science 348, 683-640 (2015).

7. Bastin, J. F. et al. The global tree restoration potential. Science 365, 76-79 (2019).

8. IPCC Special Report on Climate Change and Land (eds Shukla, P. R. et al.) (2019).

9. Miller, D. C. \& Hajjar, R. Forests as pathways to prosperity: empirical insights and conceptual advances. World Development (in the press).

10. Liu, J. et al. Systems integration for global sustainability. Science $\mathbf{3 4 7}$, 1258832 (2015).

11. Lenzen, M. et al. International trade drives biodiversity threats in developing nations. Nature 486, 109-112 (2012).

12. Sheldon, T. \& Sankaran, C. The impact of Indonesian forest fires on Singaporean pollution and health. Am. Econ. Rev. 107, 526-529 (2017).

13. Sutherland, W. J., Fleishman, E., Mascia, M. B., Pretty, P. \& Rudd, M. A. Methods for collaboratively identifying research priorities and emerging issues in science and policy. Methods Ecol. Evol. 2, 238-247 (2011).

14. Cabinet Office. Horizon Scanning Programme: a New Approach for Policy Making (UK Government Office for Science, 2013).

15. Sutherland, W. J. et al. Ten years on. A review of the first global conservation horizon scan. Trends Ecol. Evol. 34, 139-153 (2019).

16. Bengston, D. N. Horizon Scanning for Environmental Foresight: a Review of Issues and Approaches Report No. GTR-NRS-121 (U. S. D. A. Forest Service, 2013).

17. Statement on the Status of the Global Climate in 2018 (World Meteorological Organization, 2018).
18. Millar, C. I. \& Stephenson, N. L. Temperate forest health in an era of emerging megadisturbance. Science 349, 823-826 (2015).

19. Hubbart, J. A., Guyette, R. \& Muzika, R. M. More than drought: precipitation variance, excessive wetness, pathogens and the future of the western edge of the eastern deciduous forest. Sci. Total Environ. 566, 463-467 (2016).

20. Brienen, R. J. W. et al. Long-term decline of the Amazon carbon sink. Nature 519, 334-348 (2015)

21. Lawrence, D. \& Vandecar, K. Effects of tropical deforestation on climate and agriculture. Nat. Clim. Change 5, 27-36 (2015).

22. IPBES. Summary for Policymakers. In The Global Assessment Report on Biodiversity and Ecosystem Services of the Intergovernmental Science-Policy Platform on Biodiversity and Ecosystem Services (IPBES secretariat, 2019).

23. Smith, A. M. S. et al. The science of firescapes: achieving fire-resilient communities. BioScience 66, 130-146 (2016).

24. Olivero, J. et al. Recent loss of closed forests is associated with Ebola virus disease outbreaks. Sci. Rep. 7, 142971 (2017).

25. De Pinto, A. et al. The role of crop production in the forest landscape restoration approach - assessing potential benefits of meeting the Bonn Challenge. Front. Sustain. Food Syst. 4, 61 (2020).

26. Hecht, S. et al. People in motion, forests in transition: trends in migration, urbanization, and remittances and their effects on tropical forests (Center for International Forestry Research (CIFOR), 2015).

27. Knight, J. \& Gunatilaka, R. Great expectations? The subjective well-being of rural-urban migrants in China. World Dev. 38, 113-124 (2010).

28. Oldekop, J. A., Sims, K. R. E., Whittingham, M. J. \& Agrawal, A. An upside to globalization: International migration drives reforestation in Nepal. Glob. Environ. Chang. 52, 66-74 (2018).

29. Robson, J. \& Berkes, F. How does out-migration affect community institutions. A study of two indigenous municipalities in Oaxaca, Mexico. Hum. Ecol. 39, 179-190 (2011).

30. Montefrio, M. J. F., Ortiga, Y. Y. \& Josol, M. R. C. B. Inducing development: social remittances and the expansion of oil palm. Int. Migr. Rev. 48, 216-242 (2014)

31. Van Hear, N., Bakewell, O. \& Long, K. Push-pulls plus: reconsidering drivers of migration. J. Ethn. Migr. Stud. 44, 927-944 (2018).

32. Fischer, J. et al. Land sparing versus land sharing: moving forward. Conserv. Lett. 7, 149-157 (2014).

33. Davis K. F. et al. Tropical forest loss enhanced by large-scale land acquisitions. Nat. Geosci. (in the press).

34. Pezzini, M. An emerging middle class. OECD Observer http://oecdobserver. org/news/fullstory.php/aid/3681/An_emerging_middle_class.html (2012).

35. Alexander, P. et al. Drivers for global agricultural land use change: the nexus of diet, population, yield and bioenergy. Glob. Environ. Chang. 35, 138-147 (2015).

36. Borras, S. M. Jr, Hall, R., Scoones, I., White, B. \& Wolford, W. Towards and better understanding of global land grabbing: and editorial introduction. J. Peasant Stud. 38, 209-216 (2011).

37. Curtis, P. G., Slay, C. M., Harris, N. L., Tyukavina, A. \& Hansen, M. C. Classifying drivers of global forest loss. Science 361, 1108-1111 (2018).

38. City slickers on the farm: Africa's real land grab. The Economist https://www. economist.com/middle-east-and-africa/2016/07/21/africas-real-land-grab (2016)

39. Kremen, C. \& Merenlender, A. M. Landscapes that work for biodiversity and people. Science 362, eaau6020 (2018)

40. Willet, W. et al. Food in the Anthropocene: the EAT-Lancet Commission on healthy diets from sustainable food systems. Lancet 393, 447-492 (2019).

41. Rowland, D., Ickowitz, A., Powell, B., Nasi, R. \& Sutherland, T. Forest foods and healthy diets: quantifying the contributions. Environ. Conserv. 44, 102-114 (2017)

42. Digital Dividends (World Bank, 2016).

43. Castrén, T. \& Pillai, M. Information and Communication Technology for Forest Law Enforcement and Governance (Program on Forests (PROFOR), 2015).

44. Wright, T. How many drones are smuggling drugs across the U. S. Southern Border? Air \& Space Magazine https://www.airspacemag.com/flight-today/ narcodrones-180974934/ (2020).

45. Gardner, T. A. et al. Transparency and sustainability in global commodity supply chains. World Dev. 121, 163-177 (2019).

46. Agrawal, A., Brown, D. G. \& Sullivan, J. A. Are global land grabs ticking socio-environmental bombs or just inefficient investments. One Earth $\mathbf{1}$, 159-162 (2019).

47. le Polain de Waroux, Y. et al. The restructuring of South American soy and beef production and trade under changing environmental regulations. World Dev. 121, 188-202 (2019).

48. Bebbington, A. J. et al. Resource extraction and infrastructure threaten forest cover and community rights. Proc. Natl Acad. Sci. USA 115, 13164-13173 (2018)

49. Coenen, J. et al. Environmental governance of China's Belt and Road Initiative. Environ. Policy Gov. (in the press).

50. Laurance, W. F. et al. A global strategy for road building. Nature 513, 229-232 (2014) 
51. Lees, A. C., Peres, C. A., Fearnside, P. M., Schneider, M. \& Zuanon, J. A. S. Hydropower and the future of Amazonian biodiversity. Biodivers. Conserv. 25, 451-466 (2016).

52. Golden Kroner, R. E. et al. The uncertain future of protected lands and waters. Science 364, 881-886 (2019).

53. Asner, G. P., Llactayo, W., Tupayachi, R. \& Luna, E. R. Elevated rates of gold mining in the Amazon revealed through high-resolution monitoring. Proc. Natl Acad. Sci. USA 110, 18454-18459 (2013).

54. Bebbington, A. J. et al. Priorities for governing large-scale infrastructure in the tropics. Proc. Natl Acad. Sci. USA 117, 21829-21833 (2020).

55. Walker, R. \& Simmons, C. Endangered Amazon: an indigenous tribe fights back against hydropower development in the Tapajós valley. Environment: Science and Policy For Sustainable Development 60, 4-15 (2018).

56. Kolstad, I. \& Søreide, T. Corruption in natural resource management: implications for policy makers. Resour. Policy 34, 214-226 (2009).

57. Cheng, S. H. et al. A systematic map of evidence on the contribution of forests to poverty alleviation. Environ. Evid. 8, 3 (2019).

58. Oldekop, J. A. et al. Reductions in poverty and deforestation from decentralized forest management in Nepal. Nat. Sustain. 2, 421-428 (2019).

59. Ferraro, P. J., Hanauer, M. M. \& Sims, K. R. E. Conditions associated with protected area success in conservation and poverty reduction. Proc. Natl Acad. Sci. USA 108, 13913-13918 (2011).

60. Ferraro, P. J., Sanchirico, J. N. \& Smith, M. D. Causal inference in coupled human and natural systems. Proc. Natl Acad. Sci. USA 116, 5311-5318 (2019).

61. Miller, D. C., Mansourian, S. \& Wildburger, C. (eds) Forests, Trees and the Eradication of Poverty: Potential and Limitations. A Global Assessment Report Vol. 39 (IUFRO World Series, 2020).

62. Sloan, S. The development-driven forest transition and its utility for REDD. Ecol. Econ. 116, 1-11 (2015).

63. Gelman, A. \& Imbens, A. Why ask why? Forward causal inference and reverse causal questions. National Bureau of Economic Research Working Paper 19614 (National Bureau of Economic Research, 2013).

64. Noyes, J. et al. In Cochrane Handbook for Systematic Reviews of Interventions (eds Higgins, J. P. T. et al.) 525-545 (Wiley \& Sons, Ltd., 2019).

65. Rana, P. \& Miller, D. C. Machine learning to analyze the social-ecological impacts of natural resource policy: insights from community forest management in the Indian Himalaya. Environ. Res. Lett. 14, 024008 (2019).

66. Ferraro, P. J. et al. Estimating the impacts of conservation on ecosystem services and poverty by integrating modeling and evaluation. Proc. Natl Acad. Sci. USA 112, 7420-7425 (2015)

67. Jayachandran, S. et al. Cash for carbon: a randomized trial of payment for ecosystem services to reduce deforestation. Science 357, 267-273 (2017)

68. World Bank Microdata Library. World Bank https://microdata.worldbank.org/ index.php/home (2020).

69. Shepherd, G., Kazoora, C. \& Mueller, D. Forest Livelihoods and Poverty Alleviation: The Case of Uganda. Forestry Policy and Institutions Working Paper 32 (FAO, 2013).
70. Jean, N. et al. Combining satellite imagery and machine learning to predict poverty. Science 353, 790-794 (2016).

71. Butt, N., Lambrick, F., Menton, M. \& Renwick, A. The supply chain of violence. Nat. Sustain. 2, 742-747 (2019).

72. Toumbourou, T., Muhdar, M., Werner, T. \& Bebbington, A. J. Political ecologies of the post-mining landscape: activism, resistance, and legal struggles over Kalimantan's coal mines. Energy Res. Soc. Sci. 65, 101476 (2020).

73. World Bank Open Data. World Bank https://data.worldbank.org (2019).

74. Africa in 50 Year's Time (African Development Bank, 2011).

\section{Acknowledgements}

This work was funded by the UK's Department for International Development (grant no. 203516-102) and governed by the University of Michigan's Institutional Review Board (HUM00092191). J.A.O. acknowledges the support of a European Union FP7 Marie Curie international outgoing fellowship (FORCONEPAL). L.V.R. was funded by the European Research Council (ERC) under the European Union's Horizon 2020 Research and Innovation Programme (grant agreement no. 853222 FORESTDIET). A.J.B. acknowledges the support of an Australian Research Council Australia Laureate Fellowship (grant no. FL160100072). L.B.F. acknowledges support from the European Union Marie Curie global fellowship (CONRICONF). P.M. was supported by the European Research Council (ERC) under the European Union's Horizon 2020 research and innovation program (grant agreement no. 677140 MIDLAND). R.N. was supported by the CGIAR Research Programme on Forests, Trees and Agroforestry. This Perspective contributes to the Global Land Programme (https://glp.earth).

\section{Author contributions}

J.A.O., L.V.R., A.A., C.W. and S.J.W. designed the horizon scan and convened the panel. J.A.O., L.V.R., A.A., A.J.B., P.M., D.N.B., A.B., S.B., I.D.H., P.D., S.C.D., L.B.F., T.G., C.K., K.K., D.M., T.H.M., R.N., M.N., M.A.P.V., J.M.R., W.J.S., C.W. and S.J.W. took part in the horizon scan. J.A.O. and L.V.R. drafted the initial manuscript with input from A.A., A.J.B. and P.M., which was then finalized by D.N.B., A.B., S.B., I.D.H., P.D., S.C.D., L.B.F, T.G., C.K., K.K., D.M., T.H.M., R.N., M.N., M.A.P.V., J.M.R., W.J.S., C.W. and S.J.W.

\section{Competing interests}

The authors declare no competing interests.

\section{Additional information}

Correspondence should be addressed to J.A.O.

Peer review information Nature Plants thanks Robert Kozak and Pamela McElwee for their contribution to the peer review of this work.

Reprints and permissions information is available at www.nature.com/reprints.

Publisher's note Springer Nature remains neutral with regard to jurisdictional claims in published maps and institutional affiliations.

(C) Springer Nature Limited 2020 